\title{
Nanoparticles based DNA conjugates for detection of pathogenic microorganisms
}

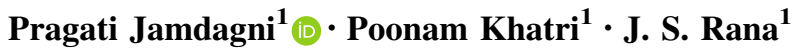

Received: 3 June 2015/ Accepted: 16 December 2015/Published online: 27 January 2016

(C) The Author(s) 2016. This article is published with open access at Springerlink.com

\begin{abstract}
Infectious diseases have been on rise in the recent past. Early diagnosis plays a role as important as proper treatment and prophylaxis. The current practices of detection are time consuming which may result in unnecessary delays in treatment. Advances in nanodiagnostic approaches have been in focus lately. The rising interest and better understanding of nanoparticles have led to opening up of new frontiers in the concerned area. Optical properties of nanoparticles are being exploited to design detection systems that can provide fast, one-step and reliable results. Based on conserved DNA sequences unique to the target organism, the results offer accuracy comparable to conventional tests. Further, visual or spectrophotometric analysis omits the need of costly apparatus for result interpretation. The present review aims at putting together the information on nanoparticles based DNA conjugate systems for detection of pathogenic microorganisms.
\end{abstract}

Keywords Nanoparticle-oligonucleotide - Conjugates · Detection $\cdot$ Microorgansims

Pragati Jamdagni

pragati_318@yahoo.co.in

Poonam Khatri

poonamkhatri2@gmail.com

J. S. Rana

jogenderrana@hotmail.com

1 Department of Biotechnology, Deenbandhu Chhotu Ram University of Science and Technology, Murthal, Sonipat, Haryana 131039, India

\section{Introduction}

Intensive studies have been conducted regarding the synthesis and applications of metal nanoparticles (NPs) in the recent past. Nanomaterials of different shapes and sizes are being synthesized and explored for their applications in various fields of life sciences. Studies are underway to determine their role in disease control in humans and plants. Their unique physicochemical properties make them special when working with modern aspects of biology and medicine [1]. However, chemical synthesis of nanoparticles might prove toxic to the environment and also their properties become dependent on the interactions between reducing agents and the metal ions and adsorption of the stabilizing agent onto the NPs [2, 3]. Hence, there is an increasing demand for techniques employing green and non toxic synthesis of metal NPs. Also, the use of biocompatible and non-toxic agents is a preferred choice for materials seeking application in biological fields.

Infectious diseases caused by microorganisms are and have always been a major threat for human lives $[4,5]$. One of the major challenges being faced by the medical fraternity is the early and accurate diagnosis of such diseases. Conventional and reliable techniques have been optimized and practiced since decades but suffer with the disadvantages of being time consuming, expensive and may be unsuitable at times [6]. Though considerable improvement in the diagnostic techniques has been seen in the recent past, identification of slow growing and fastidious pathogens has not been achieved with much success [7]. The time required for conducting conventional laboratory tests can be a major drawback when the disease has reached crucial stage and faster diagnosis is required. Keeping the above mentioned scope for such studies, an attempt has 
been made to summarize the available information in the form of a review.

\section{Molecular diagnosis}

Identification of pathogens based on their nucleic acid detection is very important in current clinical diagnosis. Each microorganism has a fragment of its genomic DNA which is conserved in itself and is preserved over generations without alterations. Detection of this DNA segment can directly confer the presence or absence of the microorganism in the test sample. This portion of DNA forms the basis of molecular detection. Such molecular tests can be broadly categorized as amplification and nonamplification based methods. While non-amplification based methods make use of hybridization strategies with DNA or RNA probes, amplification based methods rely on reactions such as polymerase chain reaction (PCR) to amplify the amount of nucleic acids for better sensitivity [8].

\section{Non-amplification based methods}

Non-amplification methods are based on direct hybridization reactions between target DNA segments and labeled DNA/RNA probes and are used when the target is in abundance. The labels could be radiolabels, fluorescent labels, enzymatic labels, chemiluminescent labels, etc. The idea behind the analysis is that signal should be emitted only when the probe is bound to the target complementary fragment of nucleic acid. When in free or unbound state, the probe must not emit a signal [8].

\section{Amplification-based methods}

Amplification-based methods come into picture when the target is present in minute quantities and direct detection cannot be trusted to yield valid results. Hence, the first requirement is to amplify either the target (target amplification) or the signals being generated by the detector molecule used (signal amplification). Signal amplification is particularly used for direct testing of biological materials; target amplification works best on processed samples [8].

A number of detection methods are currently available for target amplification systems; normal PCR, real time PCR, transcription mediated amplification (TMA), 16S rRNA amplification and sequencing, species specific gene amplification, etc. to name a few [8, 9].

The nanoparticle based DNA conjugate systems discussed below combines the goods of both the methods and provide a non-amplification based direct detection method, even when the target is present in smaller quantities. Thus, they not only possess good specificity as that of hybridization reactions but also overcome the hurdle of amplification of smaller quantity targets as in, say, PCR based detection.

\section{Nanoparticles in diagnosis}

As a result of ultra small size in the range of 1-100 $\mathrm{nm}$ [10] and high surface-to-volume ratio, NPs are blessed with distinctive physical and chemical properties [11]. These unique properties have been under continuous scrutiny since the last few decades with the aim of developing new and improved techniques focused on medical sciences. Gold and silver NPs are being extensively researched for their applications in nanodiagnostic approaches.

Pioneer studies regarding the modification of gold NPs with oligonucleotides were reported way back in 1996 (Alivastos et al. 1996; Mirkin et al. 1996, as cited in [12]) and a number of studies have been reported since then concerning gold NP-oligonucleotide conjugate systems aimed at detection of complementary DNA sequences [1316]. While gold NPs have been in prime focus, only a few reports are available for silver NPs in such systems. One of the reasons could be that synthesizing silver NPs with repeatable size is a difficult job which in turn affects its optical properties. The first report utilizing silver NPs for detection of target DNA was given by Thompson et al. [12] and they emphasized that silver NPs possess $100 \times$ greater molar extinction coefficient than gold NPs and can provide increased sensitivity at much lower concentration in both visual and absorption spectrum analysis.

\section{Principle of conjugate synthesis and detection}

The basis of conjugate systems is the ability of these NPs to conjugate with biomolecules such as DNA and proteins. Alkanethiolate monolayers onto metallic NPs are quite simple and easy to construct. However, the mechanism behind this adsorption remains unclear. One explanation could be given as oxidative addition of R-S-H to the surface of the metal coupled with the release of hydrogen gas, the equation for which is given below [17].

$\mathrm{R}-\mathrm{S}-\mathrm{H}+\mathrm{Au}_{\mathrm{n}} \rightarrow \mathrm{R}-\mathrm{S}-\mathrm{Au}++\mathrm{Au}_{\mathrm{n}-1}+1 / 2 \mathrm{H}_{2}$

Addition of these thiol moieties in nucleic acid molecules can therefore help in their adsorption in the same way.

It is well established that the electrostatic interactions of negatively charged phosphate groups of the DNA backbone and highly polarizable gold NP contribute to the stability of NP suspension against aggregation [18]. These forces provide stability to the colloid upon salt addition up to a 
concentration of $1.5 \mathrm{M} \mathrm{NaCl}$. This can be attributed to the fact that nucleic acid molecules provide buffering action for increasing the ionic strength and improve the stability. Upon increasing the salt concentration further, to $2 \mathrm{M}$ $\mathrm{NaCl}$, NP bound with ssDNA molecules start aggregating. However, if the ssDNA probes are made to hybridize with their complementary targets, they resist aggregation. This improved stability can be accredited to the buffering action in combination with the duplex which keeps the NPs linked to the nucleic acid network and prevent their aggregation [19].

One of the basic approaches for detecting hybridization on the surface of the NPs and the resultant aggregation is the surface plasmon resonance (SPR) of the solution. SPR refers to resonant oscillation of free electrons in metals on the boundary of metal surface and the surrounding medium and any change in the particle shape and size is bound to affect the SPR of the material. Aggregation of NPoligonucleotide conjugates in the presence of high salt concentrations alters the size of NPs and, hence, alters their SPR [20].

\section{Synthesis of NP-oligonucleotide conjugates}

Synthesis of NP-oligonucleotide conjugates is the first and foremost step for designing such systems since they not only detect the target but also generate result signals. Various authors have stated their protocols for the synthesis of NP-oligonucleotide conjugates [12, 13, 21-30]. These methods offer minor variations, with the basic ideology being the same.

To begin with, the oligonucleotide probes need to be modified with an alkyl thiol group to facilitate their attachment onto the NP surface (Fig. 1). It was reported that $5^{\prime}$ terminal labeling provided a better efficiency of conjugation as compared to $3^{\prime}$ terminal labeling. This could be attributed to better shielding of NPs from the ionic buffer due to increase in hydrophobicity by the alkyl chain [12]. It is also advised to first let the oligonucleotide react with reducing agents such as dithio threitol $[12,26,29,31]$ or tris(2-carboxyethyl)phosphine (TCEP) [32] so as to reduce any disulphide linkages and ensure full reactivity. If the disulphides are not reduced, active thiol group is lost, adversely affecting the monolayer assembly of oligonucleotides onto the NPs [33]. While terminal thiol modification has been conventionally used for functionalizing oligonucleotides, the conjugates synthesized with such probes may suffer from lack of stability. To overcome this problem, oligonucleotides modified with triple cyclic disulphide moieties, multiple thiols and thioctic acid have also been investigated for conjugate formation [28, 34, 35]. It was reported that presence of multiple thiol groups resulted in increased stability of the conjugates [35] because of the fact that polydentate ligands offer more stable metal-ligand complexes [36].

Once the oligonucleotides are modified and reduced, they are added to nanoparticle suspension and the resulting mixture is incubated overnight followed by the addition of phosphate buffered saline and surfactant such as sodium dodecyl sulphate. While surfactant helps in preventing aggregation [26], addition of PBS prior to adding oligonucleotide suspension can lead to irreversible aggregation of the nanoparticles by disrupting the stabilizing citrate layer on the surface as stated by Thompson and others [12]. Finally, a salting buffer is added over a period of 2 days and the solution is allowed to equilibrate overnight. Addition of salt must be gradual as charge repulsion is the main force behind maintaining the colloidal repulsion and sudden change in salt concentration could lead to irreversible aggregation. Salt, on one hand, helps in overcoming the nucleotide-metal interactions and, on the other hand, favours the adsorption of thiols onto the NP surface with steady increase in concentration. Similar methods of conjugate formation can be used for both AuNPs and AgNPs but salt increments used for AuNP reactions would lead to irreversible aggregation if used for AgNPs [31] and hence, the process needs to be carefully monitored.

A comparison of amount of DNA that could be conjugated onto gold and silver NPs showed that silver NPs offer a better coverage $\left(22.6 \pm 2.4 \mathrm{pmol} / \mathrm{cm}^{2}\right.$ for $30 \mathrm{~nm}$ silver
Fig. 1 Conjugation of thiolated oligonucleotides with metallic nanoparticles

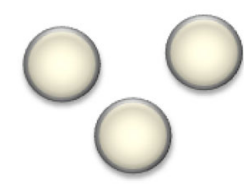

Au/ Ag NP
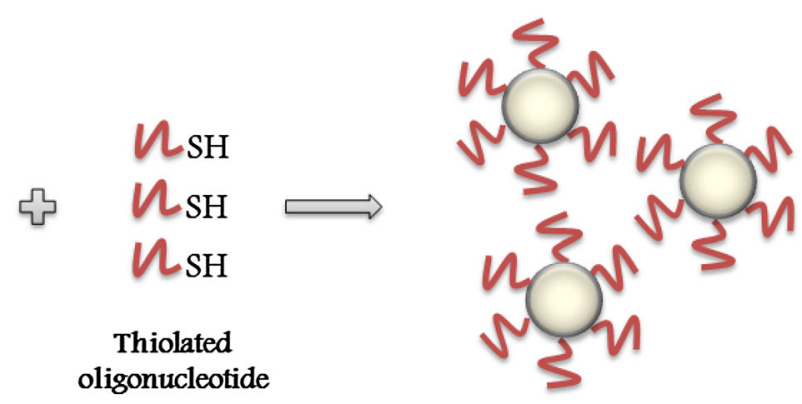

NP-oligo probe conjugate 
NP) than gold NPs $\left(15 \pm 4 \mathrm{pmol} / \mathrm{cm}^{2}\right.$ for $13 \mathrm{~nm}$ gold NP) $[12,23]$.

\section{Characterization}

Properly functionalized conjugates retain the same colour as unmodified AuNPs with no visible aggregates and can be stored in this state for 1 month [26]. NP suspension shows a shift in the surface plasmon resonance after functionalization. The absorption maxima for AuNPs was reported to shift from 518 to $523 \mathrm{~nm}$ upon oligonucleotide conjugation by Nicewarner-Pena et al. [37] and for AgNPs from 396 to $400 \mathrm{~nm}$ as stated by Vidal et al. [31]. Generation of UV-visible spectrograms at timely intervals along with visual examination can help access the stability of these conjugates. A single extinction peak ensures that no aggregation in the NP suspension resulted during the conjugation with oligonucleotides [32]. Moreover, electron microscope studies can also be undertaken to ensure oligonucleotide conjugation with NPs.

\section{Hybridization detection strategy}

Ultrasensitive DNA and RNA detection systems have been in investigation for long and these emerging techniques hold the promise of detecting even smaller and minute concentrations of biological materials omitting the need for amplification reactions such as PCR [14, 19, 38-43].

In case of nucleic acid based detection, DNA probes specific to conserved regions of pathogenic DNA can be coupled with NPs to formulate biosensors. NPs based assays can provide direct detection of genomic DNA sequence based on optical scattering properties of NPs [14]. When these conjugates encounter genomic DNA of the target organism, the probe immobilized onto the NP hybridizes with the complementary sequences in the genome. This is performed under stringent conditions such that hybridization does not occur unless the sequences are perfectly complementary to each other. On subjecting to acid/salt challenge, conjugates which successfully hybridize with the complementary DNA do not undergo acid induced aggregation, maintain their red colour while unhybridized conjugates aggregate which in turn leads to colour change from red to purple [19, 38, 39, 42, 43] (Fig. 2). This aggregation is also accompanied by an absorbance peak shift towards longer wavelength due to change in surface plasmon resonance of the NPs [38, 39]. Absorbance peak of hybridized gold NP-probe solution is observed at approximately $520 \mathrm{~nm}$ which shifts to around $575 \mathrm{~nm}$ in the absence of hybridization [43]. Hence, the effect of acid/salt induced aggregation of gold NP-probe conjugates into bigger clusters can be easily observed by visible colour change and spectrophotometric analysis of the test solutions before and after the completion of the aggregation reaction.

\section{Diagnostic applications}

\section{DNA based}

Non-specific detection of DNA sequences have been reported by a number of workers using both gold [13, 32, $44]$ and silver NPs [12, 27]. Where species specific DNA detection is concerned, studies have been published using $\mathrm{NP}$-oligonucleotide conjugates for a few pathogens, the results of which are summarized in Table 1 . The stated methods make use of detection of unamplified DNA using oligonucleotide probes as well as detection using NPoligonucleotide conjugates combined with PCR. A schematic plan of basic strategy followed for designing NP based detection systems is given in Fig. 3 .

Colorimetric assays based on NP-oligonucleotide conjugates have been developed for the detection of various pathogenic microorganisms. Probe sequences from conserved genomic regions were selected based on their uniqueness for the organism in question. They were tested so as to ensure that they do not share homology with nontarget organisms to prevent non-specific associations and hence, false positive results. These probe sequences were then conjugated with AuNPs and used for hybridization studies. Successful assays have been developed for methicillin-resistant $S$. aureus, M. tuberculosis, M. avium subsp. paratuberculosis, E. coli, S. enteritidis, S. typhimurium, Leishmania spp. and P. falciparum $[14,38-43,45$, 46] (Table 1). These systems were tested using various clinical samples and results were observed as visible colour change of the NP suspension or with the help of spectrophotometry which depicted an absorbance peak shift in case of negative hybridization.

An interesting approach involving catalytic DNA molecules, known as DNAzymes was reported by Zagorovsky and Chan. They conjugated two sets of AuNPs, A and $\mathrm{B}$, with two fragments of the DNAzyme, specific to one single gene. These fragments shared complementarities with the ends of a linker DNA, the central part of which is the target for active DNAzyme. In the presence of target gene in the test sample, the two DNAzyme fragments come in close proximity and form a complex with the target gene and the linker DNA. This interaction leads to cleaving of the linker from its central part. The cleaved linker fragments cannot link the AuNPs together and the solution remains red. In the absence of target, the linker DNA remains intact and cross links AuNP-A and AuNP-B 
Fig. 2 Schematic for gold NPoligonucleotide conjugates based detection system
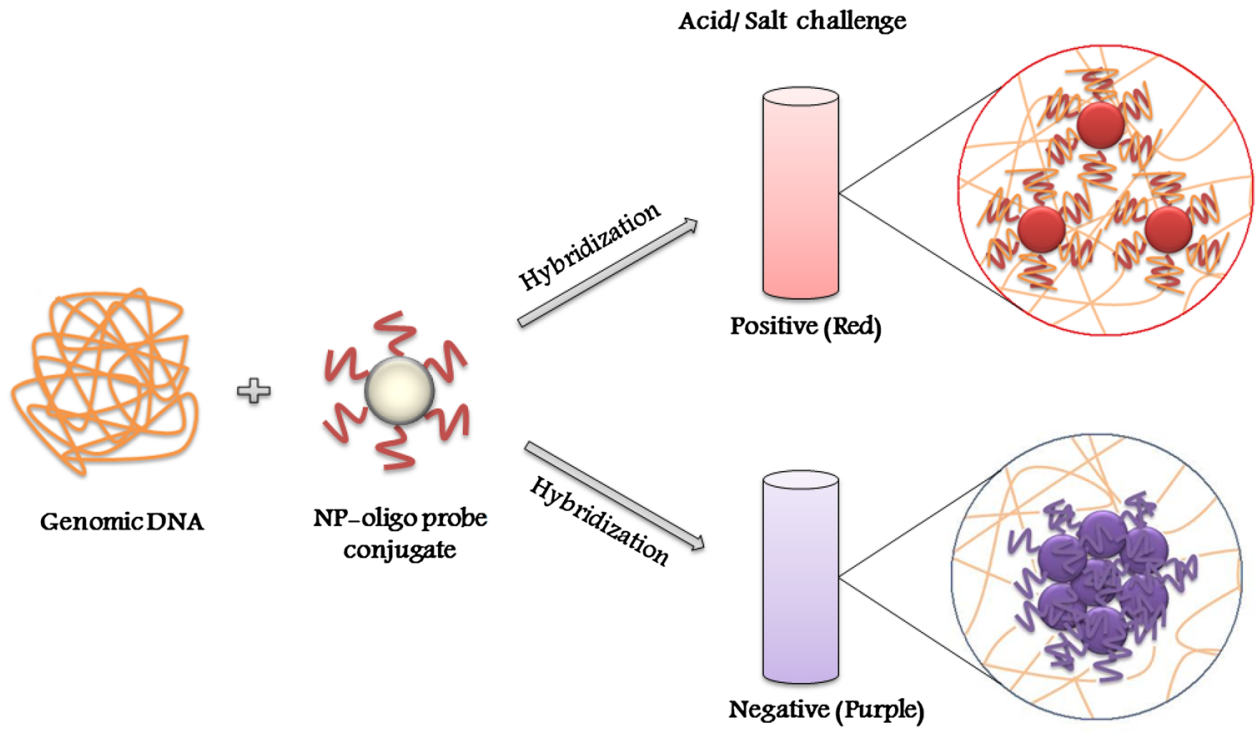

Acid/ Salt challenge

Table 1 Gold NP based detection systems for pathogenic organisms

\begin{tabular}{|c|c|c|c|c|}
\hline Target organism & Target gene & Probe sequences & $\begin{array}{l}\text { Detection } \\
\text { limit }\end{array}$ & References \\
\hline $\begin{array}{l}\text { Methicillin-resistant } \\
\text { Staphylococcus aureus }\end{array}$ & mecA & $\begin{array}{l}\text { ATGGCATGAGTAACGAAGAATA } \\
\text { TTCCAGATTACAACTTCACCA } \\
\text { AAAGAACCTCTGCTCAACAAG } \\
\text { GCACTTGTAAGCACACCTTCAT }\end{array}$ & $66 \mathrm{pg} / \mu \mathrm{l}$ & [14] \\
\hline & $23 S$ rRNA тесA & $\begin{array}{l}\text { GAGAGACAACATTTTCGACT } \\
\text { GGAACGAAGGTATCATCTTG }\end{array}$ & $\begin{array}{l}500 \mathrm{ng} \\
\text { amplicon }\end{array}$ & [45] \\
\hline Mycobacterium tuberculosis & $\begin{array}{l}\text { RNA polymerase } \\
\beta \text {-subunit }\end{array}$ & GGACGTGGAGGCGATC & $0.75 \mu \mathrm{g}$ & {$[38]$} \\
\hline $\begin{array}{l}\text { Mycobacterium avium subsp. } \\
\text { paratuberculosis }\end{array}$ & 16-23 s ITS DNA & CAGTCCGTGTGGTGTCCCT & $18.75 \mathrm{ng} / \mu \mathrm{l}$ & [39] \\
\hline Salmonella enteritidis & insertion element ( $\mathrm{Iel}$ ) & AATATGCTGCCTACTGCCCTACGCTT & $1 \mathrm{ng} / \mu \mathrm{l}$ & [40] \\
\hline Salmonella typhimurium & - & CCAAAGGCTACGCGTTAACGTGGTGTTGG & $10^{5} \mathrm{cfu} / \mathrm{ml}$ & [41] \\
\hline Escherichia coli $\mathrm{O} 157: \mathrm{H} 7$ & - & $\begin{array}{l}\text { CCGGACGCTTATGCCTTGCCATCTACAGA } \\
\text { GCAGGTGTGACGG }\end{array}$ & $10^{5} \mathrm{cfu} / \mathrm{ml}$ & [41] \\
\hline Escherichia coli & malB & ACAAAGGGAGAAGGGCATG & $11.4 \mathrm{ng}$ & [42] \\
\hline Leishmania spp. & $\begin{array}{l}\text { kinetoplast } \\
\text { minicircle DNA }\end{array}$ & $\begin{array}{l}\text { GTTAGCCGATGGTGGTCTTG } \\
\text { ACGGGTGTCTTTGATGATGC } \\
\text { TAGTCTGGTGGGATGCTTCG } \\
\text { GTGCCTTTGATGTGGGTGTT }\end{array}$ & $11.5 \mathrm{ng} / \mu \mathrm{l}$ & [43] \\
\hline Plasmodium falciparum & $\begin{array}{l}\text { Lactate } \\
\text { dehydrogenase }\end{array}$ & $\begin{array}{l}\text { CTGGGCGGTAGAACCATAGTGACCCAG } \\
\text { CCGTCTAC }\end{array}$ & $57 \mathrm{pg} / \mu \mathrm{l}$ & [46] \\
\hline
\end{tabular}

together leading to aggregation and colour change from red to purple. Different sets of AuNPs were prepared for $N$. gonorrhoeae, T. pallidum, $P$. falciparum and hepatitis B virus for rapid detection of gonorrhea, syphilis, malaria and hepatitis $\mathrm{B}$ infection. Multiplexed reaction was also observed and multiple targets were successfully detected in one experiment [47].

\section{Antibody based}

In addition to the above stated system, various other diagnostic systems have been postulated using NPs. Conjugation of NPs with antibodies in the form of immunechromatographic strip (ICS) has already been commercialized. Antibodies offer an advantage in detection as they 


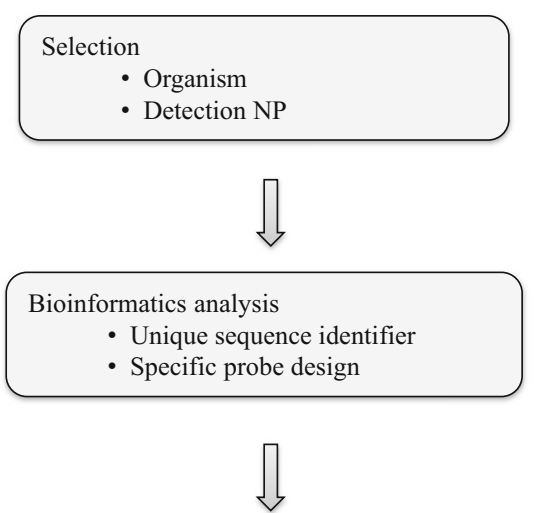

Design oligo-NP conjugates

- Thiol labeling of probe oligonucleotide

- Immobilization of oligonucleotide onto NP surface

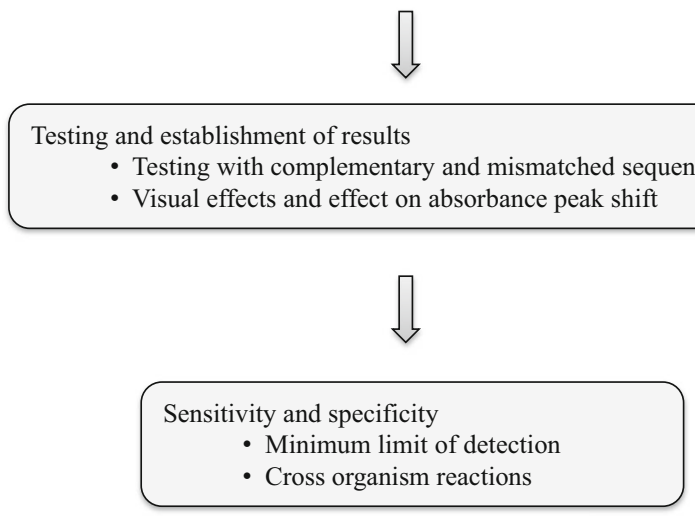

Fig. 3 Basic strategy for designing nanoparticle-oligonucleotide based detection system

can be targeted to not only the target microorganism but also to the toxins secreted and the antibodies generated by immune response [6,7]. Antibody coupled NPs have been designed for the detection of $S$. aureus in clinical samples, E. coli $\mathrm{O} 157: \mathrm{H} 7$ in food samples, multiplex detection of E. coli, S. typhimurium and $S$. aureus, detection and photo thermal lysis of $S$. typhimurium and detection of various others [48-53].

\section{Conclusion and future prospects}

Currently used detection methods rely on culturing bacterial isolates, which need an incubation period of at least $24 \mathrm{~h}$, and then testing to establish their identity, which is a time consuming work. Other systems such as enzyme immunoassays work only when the target pathogen is present in abundance [54, 55]. More specific molecular techniques such as PCR can work efficiently with lesser amount of samples but require costly apparatus.
The above stated systems can directly detect target DNA and can circumvent the need for culturing of pathogens and amplification of target DNA in the specimens. In addition of providing better detection and reliable results, these methods also allow for even easier result interpretations which can be analyzed by visible colour change and determining the shift in the absorbance spectra peak of the conjugates before and after the addition of target DNA using UV-visible spectroscopy. With both of these being fast methods, the system will not only result in faster diagnosis than conventional methods but will also provide authentic result interpretation. Also, as no special equipments or tedious protocols are required for analysis, these systems can be used as routine screening tool in clinical pathology laboratories.

However, work still needs to be done to establish the behavior of such systems when they interact with biological fluids in raw form and whether reliable results can be obtained in unprocessed samples. Also, there is a need to improve the sensitivity of these systems for better detection of pathogens present in even smaller quantities. With such advances, diagnosis of slow growing and difficult to culture fastidious microorganisms could also be done routinely with little hesitation.

Acknowledgments The author PJ is thankful to Assured Opportunity for Research Careers (AORC), Department of Science and Technology (DST), Ministry of Science and Technology, New Delhi for awarding INSPIRE fellowship.

Author's contributions This work was carried out in collaboration between all authors. PJ conceptualized and drafted the manuscript and the figures. PK coordinated the design and literature search. JSR guided technical writing and critically revised the manuscript.

\section{Compliance with ethical standards}

Conflict of interests The authors declare that they have no competing interests.

Open Access This article is distributed under the terms of the Creative Commons Attribution 4.0 International License (http://crea tivecommons.org/licenses/by/4.0/), which permits unrestricted use, distribution, and reproduction in any medium, provided you give appropriate credit to the original author(s) and the source, provide a link to the Creative Commons license, and indicate if changes were made.

\section{References}

1. Jo, Y.K., Kim, B.H., Jung, G.: Antifungal activity of silver ions and nanoparticles on phytopathogenic fungi. Plant Dis. 93(10), 1037-1043 (2009)

2. Knoll, B., Keilmann, F.: Near-field probing of vibrational absorption for chemical microscopy. Nature 399, 134-137 (1999)

3. Sengupta, S., Eavarone, D., Capila, I., Zhao, G., Watson, N., Kiziltepe, T., Sasisekharan, R.: Temporal targeting of tumour cells and neovasculature with a nanoscale delivery system. Nature 436, 568-572 (2005) 
4. Fauci, A.S.: Infectious diseases: considerations for the 21 st century. Clin. Infect. Dis. 32(5), 675-685 (2001)

5. Brachman, P.S.: Infectious diseases-past, present, and future. Int. J. Epidemiol. 32(5), 684-686 (2003)

6. Syed, M.A., Bokhari, S.H.A.: Gold nanoparticle based microbial detection and identification. J. Biomed. Nanotechnol. 7(2), 229-237 (2011)

7. Syed, M.A.: Advances in nanodiagnostic techniques for microbial agents. Biosens. Bioelectron. 51, 391-400 (2014)

8. Muldrew, K.L.: Molecular diagnostics of infectious diseases. Curr. Opin. Pediatr. 21(1), 102-111 (2009)

9. Houpikian, P., Raoult, D.: Traditional and molecular techniques for the study of emerging bacterial diseases: one laboratory's perspective. Emerg. Infect. Dis. 8(2), 122-131 (2002)

10. Chen, J.R., Miao, Y.Q., He, N.Y., Wu, X.H., Li, S.J.: Nanotechnology and biosensors. Biotechnol. Adv. 22(7), 505-518 (2004)

11. Kaittanis, C., Santra, S., Perez, J.M.: Emerging nanotechnologybased strategies for the identification of microbial pathogenesis. Adv. Drug Deliv. Rev. 62(4-5), 408-423 (2010)

12. Thompson, D.G., Enright, A., Faulds, K., Smith, W.E., Graham, D.: Ultrasensitive DNA detection using oligonucleotide-silver nanoparticle conjugates. Anal. Chem. 80(8), 2805-2810 (2008)

13. Storhoff, J.J., Elghanian, R., Mucic, R.C., Mirkin, C.A., Letsinger, R.L.: One-pot colorimetric differentiation of polynucleotides with single base imperfections using gold nanoparticle probes. J. Am. Chem. Soc. 120, 1959-1964 (1998)

14. Storhoff, J.J., Lucas, A.D., Garimella, V., Bao, Y.P., Müller, U.R.: Homogeneous detection of unamplified genomic DNA sequences based on colorimetric scatter of gold nanoparticle probes. Nat. Biotechnol. 22(7), 883-887 (2004)

15. Chen, Y., Aveyarda, J., Wilson, R.: Gold and silver nanoparticles functionalized with known numbers of oligonucleotides per particle for DNA detection. Chem. Commun. 24, 2804-2805 (2004). doi:10.1039/B411181H

16. Cai, M., Li, F., Zhang, Y., Wang, Q.: One-pot polymerase chain reaction with gold nanoparticles for rapid and ultrasensitive DNA detection. Nano Res. 3, 557-563 (2010). doi:10.1007/s12274010-0016-6

17. Pradeep, T.: Nano: The Essentials. Understanding Nanoscience and Nanotechnology, pp. 128-155. Tata McGraw-Hill Publishing Company Ltd., New Delhi (2007)

18. Sandström, P., Boncheva, M., Åkerman, B.: Nonspecific and thiol-specific binding of DNA to gold nanoparticles. Langmuir 19, 7537-7543 (2003)

19. Baptista, P., Doria, G., Henriques, D., Pereira, E., Franco, R.: Colorimetric detection of eukaryotic gene expression with DNAderivatized goldnanoparticles. J. Biotechnol. 19, 111-117 (2005)

20. Zeng, S., Baillargeat, D., Hod, H.P., Yong, K.T.: Nanomaterials enhanced surface plasmon resonance for biological and chemical sensing applications. Chem. Soc. Rev. 43, 3426-3452 (2014)

21. Mirkin, C.A., Letsinger, R.L., Mucic, R.C., Storhoff, J.J.: A DNA-based method for rationally assembling nanoparticles into macroscopic materials. Nature 382, 607-609 (1996)

22. Reynolds, R.A., Mirkin, C.A., Letsinger, R.L.: Homogeneous, nanoparticle-based quantitative colorimetric detection of oligonucleotides. J. Am. Chem. Soc. 122, 3795-3796 (2000)

23. Demers, L.M., Mirkin, C.A., Mucic, R.C., Reynolds III, R.A., Letsinger, R.L., Elghanian, R., Viswanadham, G.: A fluorescence-based method for determining the surface coverage and hybridization efficiency of thiol-capped oligonucleotides bound to gold thin films and nanoparticles. Anal. Chem. 72, 5535-5541 (2000)

24. Storhoff, J.J., Elghanian, R., Mirkin, C.A., Letsinger, R.L.: Sequence-dependent stability of DNA-modified gold nanoparticles. Langmuir 18, 6666-6670 (2002)
25. Sato, K., Hosokawa, K., Maeda, M.: Rapid aggregation of gold nanoparticles induced by non-cross-linking DNA hybridization. J. Am. Chem. Soc. 125(27), 8102-8103 (2003)

26. Hill, D.H., Mirkin, C.A.: The bio-barcode assay for the detection of protein and nucleic acid targets using DTT-induced ligand exchange. Nat. Protoc. 1(1), 324-336 (2006)

27. Liu, C.H., Li, Z.P., Du, B.A., Duan, X.R., Wang, Y.C.: Silver nanoparticle-based ultrasensitive chemiluminescent detection of DNA hybridization and single-nucleotide polymorphisms. Anal. Chem. 78(11), 3738-3744 (2006)

28. Lee, J.S., Lytton-Jean, A.K., Hurst, S.J., Mirkin, C.A.: Silver nanoparticle-oligonucleotide conjugates based on DNA with triple cyclic disulfide moieties. Nano Lett. 7(7), 2112-2115 (2007)

29. Thompson, D.G., Faulds, K., Smith, W.E., Graham, D.: Precise control of the assembly of dye-coded oligonucleotide silver nanoparticle conjugates with single base mismatch discrimination using surface enhanced resonance raman scattering. J. Phys. Chem. C 114(16), 7384-7389 (2010)

30. Kim, Y.S., Kim, J.H., Kim, I.A., Lee, S.J., Gu, M.B.: The affinity ratio-its pivotal role in gold nanoparticle-based competitive colorimetric aptasensor. Biosens. Bioelectron. 26, 4058-4063 (2011)

31. Vidal Jr, B.C., Deivaraj, T.C., Yang, J., Too, H.P., Chow, G.M., Gane, L.M., Lee, J.Y.: Stability and hybridization-driven aggregation of silver nanoparticle-oligonucleotide conjugates. New J. Chem. 29, 812-816 (2005)

32. Cordray, M.S., Amdahl, M., Richards-Kortum, R.R.: Gold nanoparticle aggregation for quantification of oligonucleotides: optimization and increased dynamic range. Anal. Biochem. 431(2), 99-105 (2012)

33. Zhang, D., Carr, D.J., Alocilja, E.C.: Fluorescent bio-barcode DNA assay for the detection of Salmonella enterica Serovar enteritidis. Biosens. Bioelectron. 24, 1377-1381 (2009)

34. Dougan, J.A., Karlsson, C., Smith, W.E., Graham, D.: Enhanced oligonucleotide-nanoparticle conjugate stability using thioctic acid modified oligonucleotides. Nucleic Acids Res. 35(11), 3668-3675 (2007)

35. Li, Z., Jin, R., Mirkin, C.A., Letsinger, R.L.: Multiple thiol-anchor capped DNA-gold nanoparticle conjugates. Nucleic Acids Res. 30(7), 1558-1562 (2002)

36. Cotton, F.A., Wilkinson, G., Murillo, C.A., Bochmann, M.: Advanced Inorganic Chemistry, vol. 6, pp. 27-29. Wiley, New York (1999)

37. Nicewarner-Pena, S.R., Raina, S., Goodrich, G.P., Fedoroff, N.V., Keating, C.D.: Hybridization and enzymatic extension of au nanoparticle-bound oligonucleotides. J. Am. Chem. Soc. 124(25), 7314-7323 (2002)

38. Baptista, P.V., Koziol-Montewka, M., Paluch-Oles, J., Doria, G., Franco, R.: Gold nanoparticle-probe-based assay for rapid and direct detection of Mycobacterium tuberculosis DNA in clinical samples. Clin. Chem. 52(7), 1433-1434 (2006)

39. Liandris, E., Gazouli, M., Andreadou, M., Comor, M., Abazovic, N., Sechi, L.A., Ikonomopoulos, J.: Direct detection of unamplified DNA from pathogenic mycobacteria using DNA-derivatized gold nanoparticles. J. Microbiol. Methods 78(3), 260-264 (2009)

40. Vetrone, S.A., Huarng, M.C., Alocilja, E.C.: Detection of nonPCR amplified $S$. enteritidis genomic DNA from food matrices using a gold-nanoparticle DNA biosensor: a proof-of-concept study. Sensors 12(8), 10487-10499 (2012)

41. Wu, W.H., Li, M., Wang, Y., Ouyang, H.X., Wang, L., Li, C.X., Cao, Y.C., Meng, Q.H., Lu, J.X.: Aptasensors for rapid detection of Escherichia coli $\mathrm{O} 157: \mathrm{H} 7$ and Salmonella typhimurium. Nanoscale Res. Lett. 7(1), 658-664 (2012)

42. Bakthavathsalam, P., Rajendran, V.K., Jaffar Ali, B.M.: A direct detection of Escherichia coli genomic DNA using gold 
nanoprobes. J. Nanobiotechnol. 10, 8-17 (2012). doi:10.1186/ 1477-3155-10-8

43. Andreadou, M., Liandris, E., Gazouli, M., Taka, S., Antoniou, M., Theodoropoulos, G., Tachtsidis, I., Goutas, N., Vlachodimitropoulos, D., Kasampalidis, I., Ikonomopoulos, J.: A novel nonamplification assay for the detection of Leishmania spp. in clinical samples using gold nanoparticles. J. Microbiol. Methods 96, 56-61 (2014). doi:10.1016/j.mimet.2013.10.011

44. Fujita, M., Katafuchi, Y., Ito, K., Kanayama, N., Takarada, T., Maeda, M.: Structural study on gold nanoparticle functionalized with DNA and its non-cross-linking aggregation. J. Colloid Interface Sci. 368(1), 629-635 (2012)

45. Chan, W.S., Tang, B.S., Boost, M.V., Chow, C., Leung, P.H.: Detection of methicillin-resistant Staphylococcus aureus using a gold nanoparticle-based colourimetric polymerase chain reaction assay. Biosens. Bioelectron. 53, 105-111 (2014)

46. Cheung, Y.W., Kwok, J., Law, A.W., Watt, R.M., Kotaka, M., Tanner, J.A.: Structural basis for discriminatory recognition of Plasmodium lactate dehydrogenase by a DNA aptamer. Proc. Natl. Acad. Sci. USA 110(40), 15967-15972 (2013)

47. Zagorovsky, K., Chan, W.C.W.: A plasmonic DNAzyme strategy for point-of-care genetic detection of infectious pathogens. Angew. Chem. Int. Ed. 52, 3168-3171 (2013)

48. Huang, S.H.: Gold nanoparticle-based immunochromatographic test for identification of Staphylococcus aureus from clinical specimens. Clin. Chim. Acta 373, 139-143 (2006)

49. Huang, P.J., Tay, L.L., Tanha, J., Ryan, S., Chau, L.K.: Singledomain antibody-conjugated nanoaggregate-embedded beads for targeted detection of pathogenic bacteria. Chem. Eur. J. 15, 9330-9334 (2009)

50. Varshney, M., Li, Y.: Interdigitated array microelectrode based impedance biosensor coupled with magnetic nanoparticle-antibody conjugates for detection of Escherichia coli $\mathrm{O} 157: \mathrm{H} 7$ in food samples. Biosens. Bioelectron. 22, 2408-2414 (2007)

51. Wang, L., Zhao, W., O'Donoghue, M.B., Tan, W.: Fluorescent nanoparticles for multiplexed bacteria monitoring. Bioconjug. Chem. 18(2), 297-301 (2007)

52. Wang, S., Singh, A.K., Senapati, D., Neely, A., Yu, H., Ray, P.C.: Rapid colorimetric identification and targeted photothermal lysis of Salmonella bacteria by using bioconjugated oval-shaped gold nanoparticles. Chem. Eur. J. 16, 5600-5606 (2010)

53. Phillips, R.L., Miranda, O.R., You, C.C., Rotello, V.M., Bunz, U.H.F.: Rapid and efficient identification of bacteria using goldnanoparticle-poly(para-phenyleneethynylene) constructs. Angew. Chem. Int. Ed. 47, 2590-2594 (2008)

54. Bennett, A.R., MacPhee, S., Betts, R.P.: The isolation and detection of Escherichia coli $\mathrm{O} 157$ by use of immunomagnetic separation and immunoassay procedures. Lett. Appl. Microbiol. 22(3), 237-243 (1996)

55. Chapman, P.A., Ellin, M., Ashton, R.: A comparison of immunomagnetic separation and culture, Reveal ${ }^{\mathrm{TM}}$ and VIP ${ }^{\mathrm{TM}}$ for detection of $E$. coli $\mathrm{O} 157$ in enrichment cultures of naturally contaminated raw beef, lamb and mixed meat products. Lett. Appl. Microbiol. 32(3), 171-175 (2001) 